\title{
Descemet Membrane Injury Caused by Forceps Delivery
}

\author{
Jing Xie, Chenxing Zhang and Tao Yu* \\ Southwest Hospital/Southwest Eye Hospital, China \\ *Corresponding author: Tao Yu, Southwest Hospital/Southwest Eye Hospital, Chongqing, 400038, P.R. China
}

\begin{tabular}{|c|c|}
\hline ARTICLE INFO & ABSTRACT \\
\hline $\begin{array}{l}\text { Received: 蔧 July 22, } 2019 \\
\text { Published: 幽 August 02, } 2019\end{array}$ & $\begin{array}{l}\text { We present a case of a 21-year-old man who reported to our out-patient department } \\
\text { complaining of the left eye was unclear since childhood. Slit lamp bio microscopy showed } \\
\text { a distinctive oblique vertical line situated on the posterior surface of the cornea. Corneal }\end{array}$ \\
\hline $\begin{array}{l}\text { Citation: Jing Xie, Chenxing Zhang, Tao } \\
\text { Yu. Descemet Membrane Injury Caused } \\
\text { by Forceps Delivery. Biomed J Sci \& Tech } \\
\text { Res 20(2)-2019. BJSTR. MS.ID.003422. } \\
\text { Keywords: Obstetric Injury; Forceps; } \\
\text { Descemet Membrane; Cornea; AS-OCT }\end{array}$ & $\begin{array}{l}\text { From ultrasound bio microscopy (UBM) we could see a membranous hypoechoic on the } \\
\text { posterior surface of the left cornea. Anterior segment optical coherence tomography (AS- } \\
\text { OCT) demonstrated bandlike structures protruding from the cornea into the anterior } \\
\text { chamber. The patient had a history of complicated, in-hospital, forceps-assisted delivery. } \\
\text { The perinatal ophthalmic history was noncontributory. The fellow eye was healthy. We } \\
\text { conclude that AS-OCT is useful in confirming the clinical diagnosis of suspected perinatal } \\
\text { corneal trauma because of the specific appearance of the Descemet membrane hypertrophic } \\
\text { ridge in those examinations. }\end{array}$ \\
\hline
\end{tabular}

\section{Introduction}

Corneal edema occurred in the process of childbirth is caused by the eyeball being squeezed toward the sacral direction during production, causing the cornea to expand horizontally, resulting in tearing of the posterior elastic membrane in the vertical or oblique direction [1]. It can occur during natural childbirth, more commonly when using forceps [2]. The child was born with corneal opacity and edema, and then the symptoms gradually relieved. However, the linear opacity of the posterior surface of the cornea in the vertical or oblique direction is still present, and the number of corneal endothelial cells is reduced compared with the contralateral eye [3], and therefore, corneal edema may occur after adulthood. Other clinical manifestations include corneal astigmatism [1] or depression of the contralateral occipital [3]. The corneal injury caused by forceps is often misdiagnosed clinically. We report the clinical features of corneal injury caused by forceps and the characteristics of anterior segment OCT to improve the understanding of the disease.

The patient, male, 21 years old, complained that the left eye was unclear since childhood. No history of systemic disease, history of traumatic eyes, and history of eye diseases. Ask the patient's parents about the medical history, the patient's birth process is applied to the production forceps, and other aspects of the perinatal period are not special. Eye examination: Vision: 0.05 in the right eye, correction: $-8.75 \mathrm{DS} /-2.00 \mathrm{DC}^{*} 108^{\circ} \rightarrow 0.9$, left eye: finger counting $/ 20 \mathrm{~cm}$, correction: $-9.00 \mathrm{DS} /-6.00 \mathrm{DC}^{*} 160^{\circ} \rightarrow 0.02$. Intraocular pressure measurement: $16 \mathrm{mmHg}$ in the right eye and $19 \mathrm{mmHg}$ in the left eye (non-contact tonometer). Eye axis: right eye: $27.01 \mathrm{~mm}$, left eye: $28.61 \mathrm{~mm}$. Slit lamp microscopy: no abnormalities in the right cornea (Figure 1A). The cornea of the middle part of the left eye was gray and turbid, and the size was about $5^{*} 3 \mathrm{~mm}^{2}$ (Figure $1 \mathrm{~B}$, thick arrow). The translucent linear opacity (Figure 1B, thin arrow) was observed under the ridge of the turbid area. Slit lamp examination revealed corneal opacity mainly in the posterior and posterior elastic membranes (Figure 1C, arrow). No blister formation was observed on the corneal epithelial surface. There was no obvious abnormality in the anterior chamber, lens and vitreous examination of both eyes, and the fundus examination showed a high myopia change (Figure 1). 


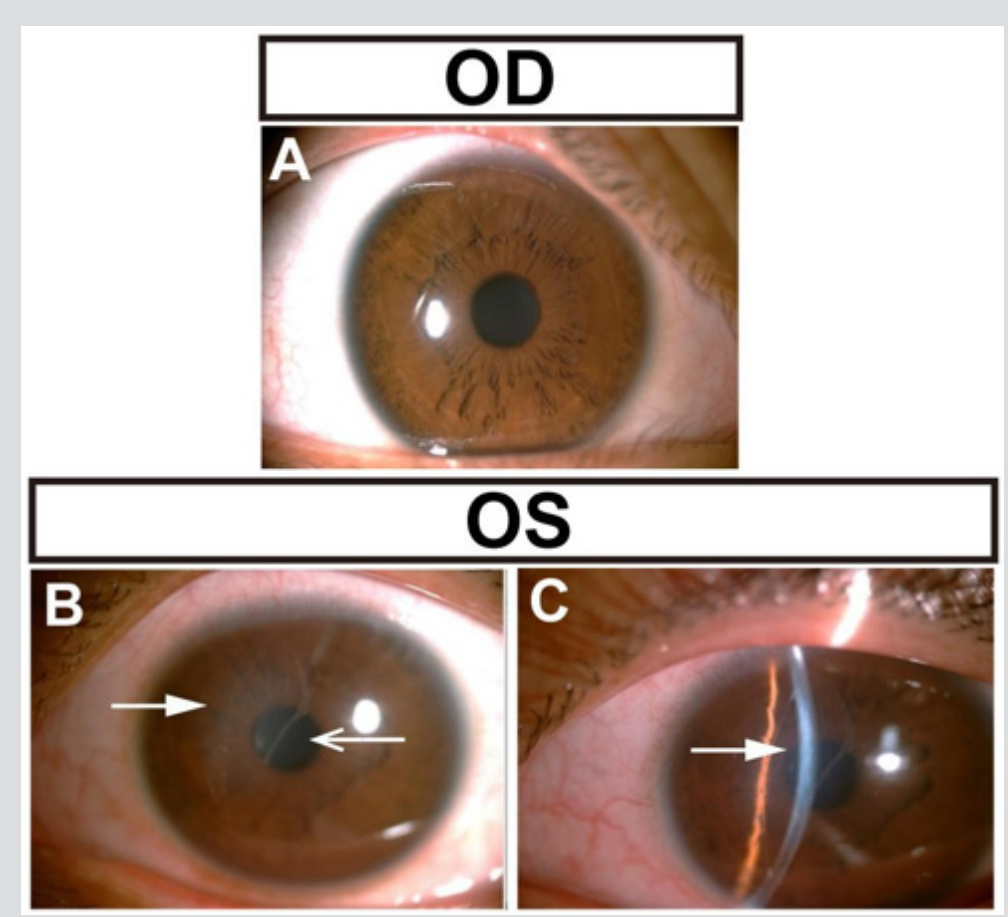

Figure 1: Photography of both eyes. A: Photography of right eye showed normal. B, C: Photography of left eye showed the middle part of cornea was gray and turbid.

Corneal topography (Schwind Sirius, Germany): no obvious abnormalities in the right cornea, increased corneal curvature of the left eye, and irregular astigmatism (Figure 2). Ultrasound biomicroscopy (SUOER, SW-300, Sower Electronics Technology Co., Ltd., Tianjin): No abnormalities in the right eye. A membranous hypoechoic is seen on the posterior surface of the left cornea (Figure 3, arrow). Anterior segment optical coherence tomography (AS-OCT) (RTVue, Optovue, USA): no abnormalities in the right eye.
A membrane is visible on the posterior surface of the left cornea, one end of which protrudes from the anterior chamber (Figure 4, thick arrow) and the other end is curled (Figure 4, thin arrow). The nasal side of cornea was significantly thicker, with a thickness of $895 \mu \mathrm{m}$. Corneal endoscopy (SP.3000P, Topcon, Japan): The corneal endothelium of the right eye was 2674.6 cells $/ \mathrm{mm}^{2}$, and the structure of the left corneal endothelial cells was unclear (Figure 5).

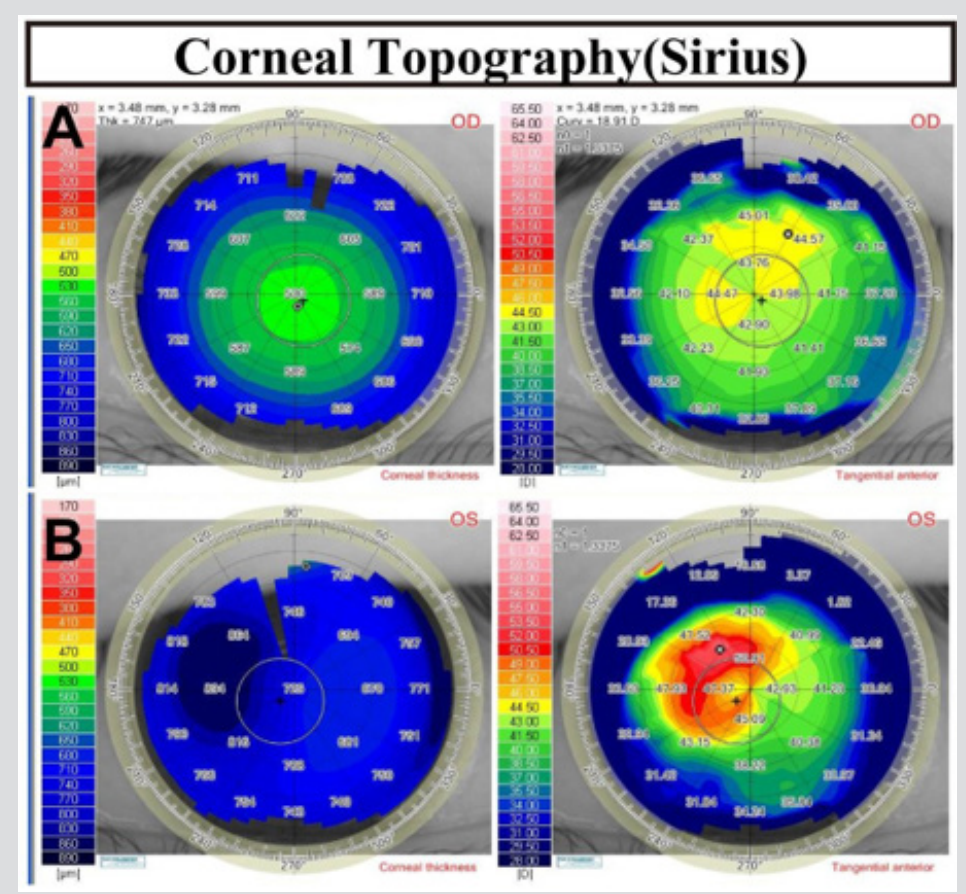

Figure 2: Corneal topographic examination of both eyes. A: The right eye was normal. B: There was irregular astigmatism in the nasal side of cornea. 


\section{Ultrasound Biomicroscope(UBM)}
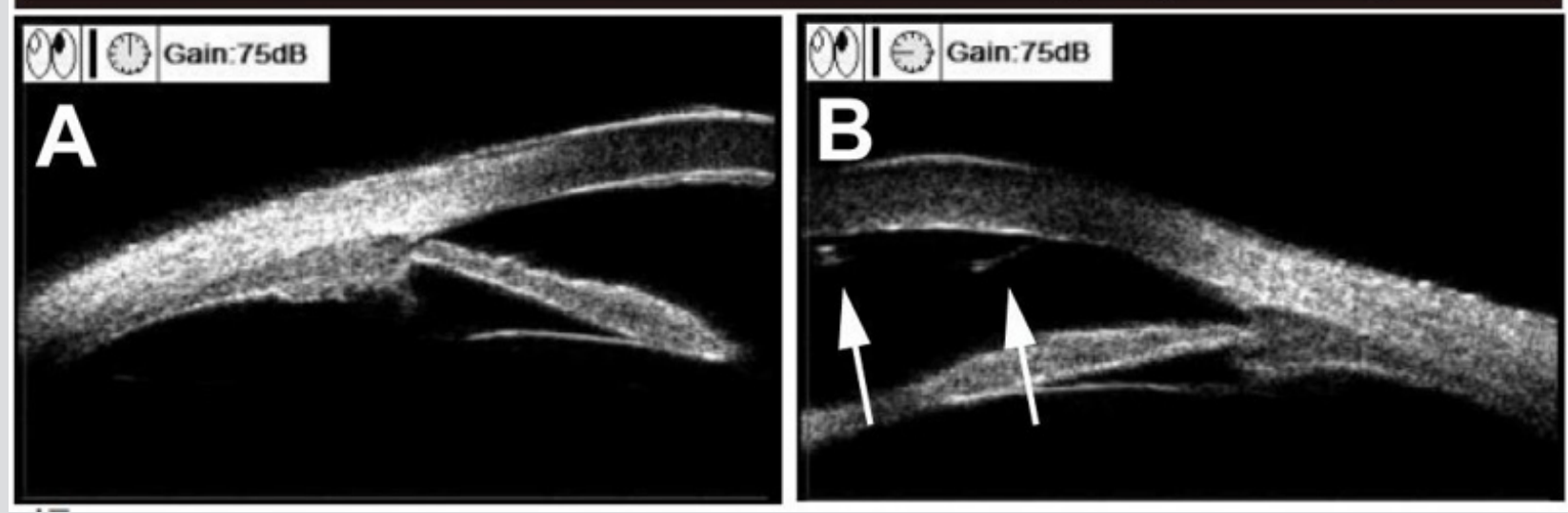

Figure 3: UBM examination showed membranous hypoechoic (arrow) on the endothelium of left eye.

\section{Optical Coherence Tomograph(OCT)}
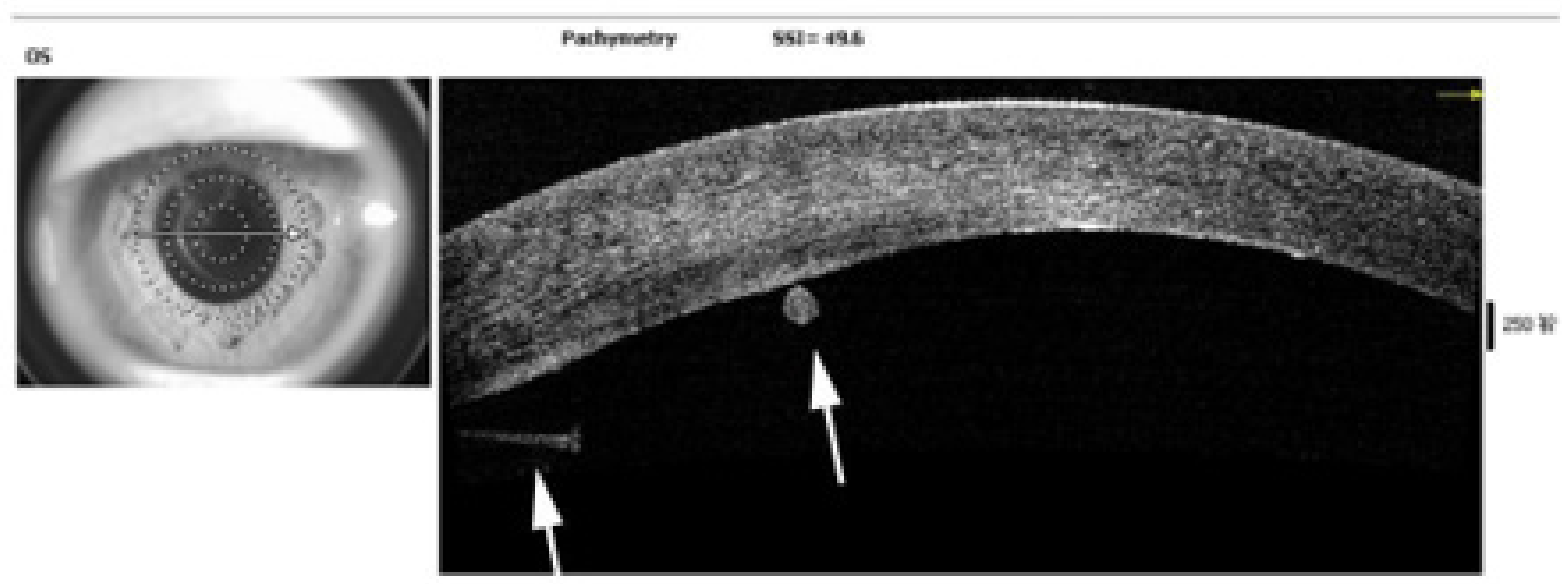

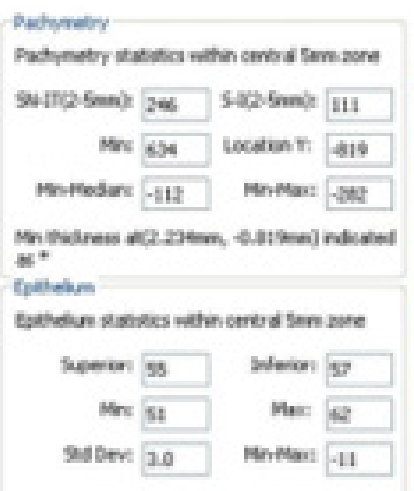

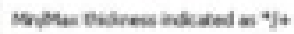
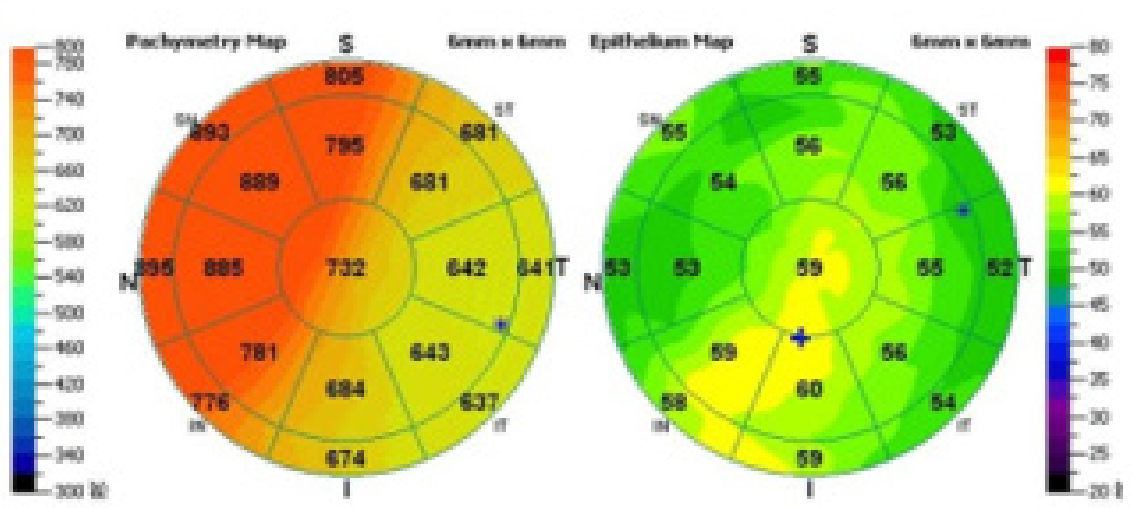

Figure 4: The corneal endothelium is visible in the membrane, one end protrudes from the front chamber, the other end is curled, and the cornea is thickened significantly in nasal side. 


\section{Corneal endothelium cells}
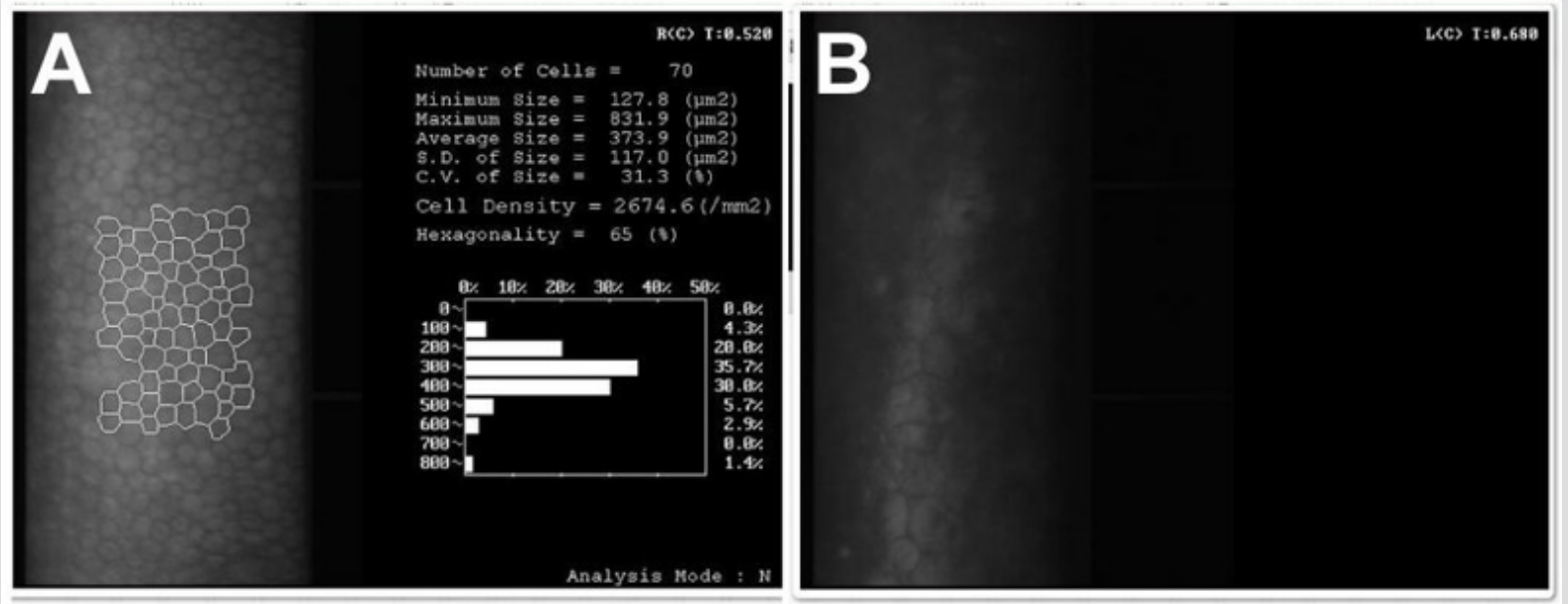

Figure 5: Corneal endoscopy of both eyes. A: The right eye showed normal. B: The structure of endothelial cells is unclear in the left eye.

\section{Diagnosis}

Left eye corneal forceps injury left eye amblyopia, high myopia of both eyes. Since the patient's left eye does not currently have signs of macro vesicular keratopathy, we will review the patient regularly to observe the presence or absence of corneal endothelial decompensation.

\section{Discussion}

We report the clinical features of a patient with corneal injury caused by forceps. Slit lamp microscope and anterior segment OCT examination showed a membrane on the posterior surface of the cornea, accompanied by a vertical-slanted band-like structure protruding into the anterior chamber, and the cornea thickened at the injury site. Combined with the application history of the forceps at the time of birth, it is consistent with the diagnosis of corneal injury caused by forceps. Histologically, there are four types of postcorneal elastic membrane rupture caused by forceps injury $[1,4]$. The patients reported herein conformed to type I, the posterior corneal tears in the Descemet membrane, one end protruding into the front chamber, and the other end forming a curl. Histological examination suggests [1] that the band-like structure of the anterior chamber may represent the post-elastic membrane component of the hypertrophy during the healing process.

The differential diagnosis of corneal injury caused by forceps mainly includes congenital glaucoma, congenital hereditary corneal endothelial dystrophy, von Hippel intrauterine ulcer, and Peter abnormality. However, with the regression of corneal edema, a typical posterior corneal tear in the Decemet membrane and a film on the posterior surface of the cornea are clearly diagnosed [5]. In most cases, corneal edema caused by forceps will resolve by itself within a few weeks and does not require special treatment [5]. Post-corneal elastic membrane rupture can cause corneal astigmatism [6].
Angell et al reported that the average corneal astigmatism due to forceps was 6.9D (3.0-10.50D) compared to 0.36D astigmatism $(0.0-1.50 \mathrm{D})$ in the contralateral eye, and the steep axis of astigmatism paralleled the axis of posterior elastic membrane rupture [7]. High astigmatism of the cornea or corneal opacity can cause amblyopia. Patients need to undergo ciliary muscle paralysis optometry and wear glasses or contact lenses to diagnose and treat refractive errors, cover healthy eyes to treat amblyopia.

If corneal opacity or corneal edema caused by corneal edema continues to develop, a corneal transplant is required. Within one year of birth, if accurate refractive correction combined with healthy eye masking is not performed, the improvement in vision will be significantly limited $[8,9]$. Amblyopia after corneal endothelial transplantation remains a major factor limiting visual acuity [10]. Early correction of refractive and amblyopia in patients with corneal damage caused by forceps will have a positive effect on visual function improvement. The forceps of the cornea are often monocular, and the size of the posterior elastic membrane is different. Due to the occlusion of corneal edema, damage to the posterior elastic membrane may not be observed in the early stage, causing diagnostic difficulties. For corneal opacity after birth, routine OCT examination is required. The characteristic examination results of OCT and detailed medical history inquiry can confirm the diagnosis.

\section{Acknowledgment}

The authors would like to convey great thanks to all the laboratory staff who were involved in this work.

\section{References}

1. McDonald MB, Burgess SK (1992) Contralateral occipital depression related to obstetric forceps injury to the eye. American journal of ophthalmology 114(3): 318-321. 
2. Lisch W (1976) Corneal lesion by vacuum extraction (author's transl) Klinische Monatsblätter für Augenheilkunde 169(4): 520-523.

3. Hofmann RF, Paul TO, Pentelei Molnar J (1981) The management of corneal birth trauma. Journal of pediatric ophthalmology and strabismus 18(1): 45-47.

4. Honig MA, Barraquer J, Perry HD, Riquelme JL, Green WR (1996) Forceps and vacuum injuries to the cornea: histopathologic features of twelve cases and review of the literature. Cornea 15(5): 463-472.

5. Scorcia V, Pietropaolo R, Carnevali A, De Luca V, Lucisano A, et al. (2016) Results of Descemet Stripping Automated Endothelial Keratoplasty for the Treatment of Late Corneal Decompensation Secondary to Obstetrical Forceps Trauma. Cornea 35(3): 305-307.

6. Suma Ganesh, Priyanka Arora, Kamaldeep Arora (2013) Descemet membrane breaks following forceps delivery. Indian pediatrics 50: 257.

ISSN: 2574-1241

DOI: 10.26717/BJSTR.2019.20.003422

Tao Yu. Biomed J Sci \& Tech Res

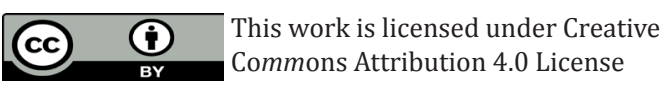

Submission Link: https://biomedres.us/submit-manuscript.php
7. Angell LK, Robb RM, Berson FG (1981) Visual prognosis in patients with ruptures in Descemet's membrane due to forceps injuries. Archives of ophthalmology 99(12): 2137-2139.

8. Harvey EM, Dobson V, Miller JM, Sherrill DL (2004) Treatment of astigmatism-related amblyopia in 3- to 5-year-old children. Vision research 44(14): 1623-1634.

9. Kobayashi A, Yokogawa H, Mori N, Sugiyama K (2015) Case series and techniques of Descemet's Stripping Automated Endothelial Keratoplasty for severe bullous keratopathy after birth injury. BMC ophthalmology 15: 92.

10. Hayashi T, Hirayama Y, Yamada N, Shimazaki Den S, Shimazaki J (2013) Descemet stripping automated endothelial keratoplasty for bullous keratopathy with an irregular posterior surface. Cornea 32(9): 11831188.

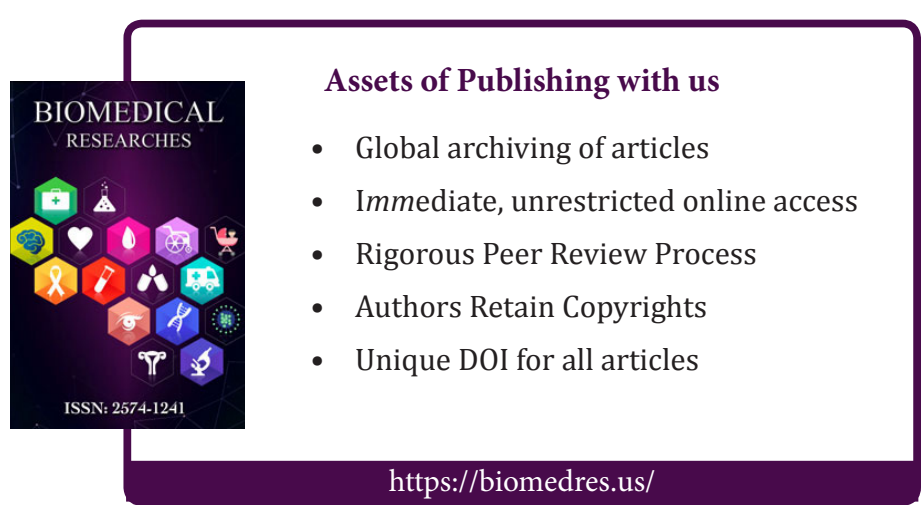

